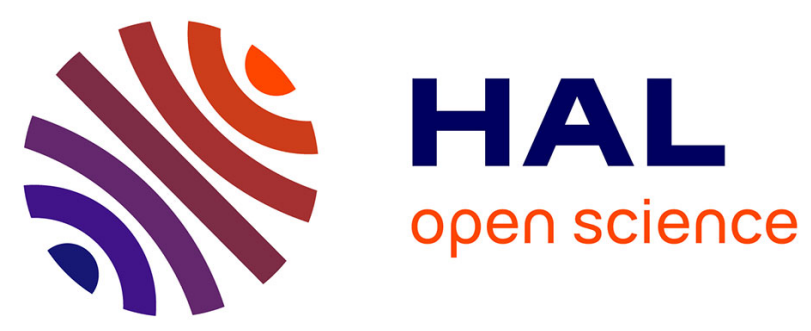

\title{
Oak powdery mildew changes growth patterns in its host tree: host tolerance response and potential manipulation of host physiology by the parasite
}

Marie-Laure Desprez-Loustau, Gilles Saint-Jean, Benoît Barrès, Cécile Françoise Dantec, Cyril Dutech

\section{To cite this version:}

Marie-Laure Desprez-Loustau, Gilles Saint-Jean, Benoît Barrès, Cécile Françoise Dantec, Cyril Dutech. Oak powdery mildew changes growth patterns in its host tree: host tolerance response and potential manipulation of host physiology by the parasite. Annals of Forest Science, 2014, 71 (5), pp.563 - 573. 10.1007/s13595-014-0364-6 . hal-01102591

\section{HAL Id: hal-01102591 \\ https://hal.science/hal-01102591}

Submitted on 13 Jan 2015

HAL is a multi-disciplinary open access archive for the deposit and dissemination of scientific research documents, whether they are published or not. The documents may come from teaching and research institutions in France or abroad, or from public or private research centers.
L'archive ouverte pluridisciplinaire HAL, est destinée au dépôt et à la diffusion de documents scientifiques de niveau recherche, publiés ou non, émanant des établissements d'enseignement et de recherche français ou étrangers, des laboratoires publics ou privés. 


\title{
Oak powdery mildew changes growth patterns in its host tree: host tolerance response and potential manipulation of host physiology by the parasite
}

\author{
Marie-Laure Desprez-Loustau • Gilles Saint-Jean • \\ Benoît Barrès • Cécile Françoise Dantec • Cyril Dutech
}

Received: 8 October 2013 / Accepted: 26 January 2014 / Published online: 27 February 2014

(C) INRA and Springer-Verlag France 2014

\begin{abstract}
- Context Parasites can induce strong effects on their host's growth, not only as a result of host resource exploitation (growth loss) but also with a potential adaptive value for host (tolerance response) and themselves (increased transmission). - Aims We assessed these three types of phenotypic changes in oak seedlings infected by powdery mildew.

- Methods A manipulative field experiment with three levels of parasite inoculum was designed in order to tease apart infection from genetic effects on oak growth. Seedlings were monitored during 3 years for height growth, phenology and infection.

- Results Powdery mildew infection induced both significant growth loss and qualitative changes in plant architecture. The
\end{abstract}

Handling Editor: Erwin Dreyer

Contribution of the co-authors MLD-L: conceived the experiment and performed data analysis.

MLD-L and GS-J: ran the experiment and collected the data.

MLD-L, BB, CDa and CDu: interpreted data and wrote the paper.

Electronic supplementary material The online version of this article (doi:10.1007/s13595-014-0364-6) contains supplementary material, which is available to authorized users.

M.-L. Desprez-Loustau $(\bowtie) \cdot$ G. Saint-Jean $\cdot$ B. Barrès •

C. F. Dantec $\cdot$ C. Dutech

BIOGECO UMR 1202, INRA, 69 route d'Arcachon, 33610 Cestas,

France

e-mail: loustau@bordeaux.inra.fr

M.-L. Desprez-Loustau • G. Saint-Jean • B. Barrès • C. F. Dantec •

C. Dutech

BIOGECO UMR 1202, Univ. Bordeaux, 351 Cours de la Libération,

33400 Talence, France

Present Address:

B. Barrès

Metapopulation Research Group, University of Helsinki,

00014 Helsinki, Finland most striking and unexpected change was increased growth polycyclism in infected seedlings. This benefitted both the host as a form of compensation for infection-caused height loss, and the pathogen, by increasing sporulation.

- Conclusion The study highlights the effect of parasites in the expression of plant phenotypic traits, such as phenology and ultimately tree architecture. Both host tolerance and parasitic manipulation may be involved in the observed changes in growth patterns. These results suggest a complex interplay between development and defence in trees and emphasize the need to better assess tolerance mechanisms when considering the defence strategies of trees against pathogens.

Keywords Tolerance $\cdot$ Phenology $\cdot$ Polycyclism $\cdot$ Rhythmic growth $\cdot$ Powdery mildew $\cdot$ Oak

\section{Introduction}

Trees have to cope with many pathogens during their lifetime. Pathogen impact may be especially important in natural regenerations where high density of seedlings favours disease transmission (Augspurger 1984; Packer and Clay 2000). Pathogens derive their nutrition from their host trees and cause damage to invaded tissues and organs, thus finally reducing host fitness (Gilbert 2002). However, changes induced by pathogens or parasites in their hosts also include phenotypic changes affecting a variety of traits, such as morphology, phenology and timing of reproduction (Michalakis 2007; Pagan et al. 2008). When alterations in plant life-history traits mitigate negative effects of damage, either by phenotypic plasticity or genetic adaptation, these changes can be viewed as a host defence strategy (Pagan et al. 2008). The tolerance concept was defined by evolutionary biologists as referring to host traits that do not reduce or eliminate infection, but that 
reduce or compensate its fitness consequences (Roy and Kirchner 2000). Tolerance has been suggested to play an important role in the evolution of plant-parasite interactions in natural populations (Roy and Kirchner 2000). It has been well documented in plant-herbivore interactions (Fornoni 2011; Baucom and de Roode 2011). However, it has received modest attention so far in plant pathology, including for trees, compared to the resistance component of the plant defence strategy, i.e. the ability to prevent infection (e.g. Dangl et al. 2013; Kovalchuk et al. 2013).

Parasites may also benefit from infection-induced modifications of their hosts. The concept of host manipulation by parasites was first used in animal-parasite studies. Aberrant, even suicidal, behaviour of infected hosts strongly suggested that parasites have the potential to alter a broad range of phenotypic traits in their hosts to their own benefit, in particular by increasing their transmission (Poulin 2010). In the absence of "plant behaviour," this concept has been understandably much less used for plant — than for animal — parasite systems, although it was extended to deal with changes in plant developmental patterns (Shykoff and Kaltz 1998; Montarry et al. 2007).

Here, we focus on oak powdery mildew which is an interesting biological model both for its environmental significance and for characteristics of the host-pathogen interaction. The disease, caused by a complex of fungal species, especially Erysiphe alphitoides (Griffon and Maubl.) U. Braun and S. Takam. and Erysiphe quercicola U. Braun and S. Takam., occurs all over Europe on deciduous oaks (especially Quercus robur L.) (Mougou et al. 2008; Mougou-Hamdane et al. 2010). Severe foliar infection can lead to mortality in young seedlings and in mature trees when associated with other factors of decline (Marçais and Desprez-Loustau 2013). Powdery mildew fungi are biotrophic parasites that derive nutrients from the living cells of their hosts, thanks to highly specialized structures called haustoria. These structures are an active interface not only for nutrient uptake but also for the export of fungal factors, such as effectors, allowing the parasite to take control of host metabolism to its own profit (Panstruga and Dodds 2009). The highly specialized relationships between biotrophic parasites and their hosts scale up to life cycles. This is particularly critical for foliar parasites of deciduous trees in temperate regions which need to adapt to host seasonality. The phenological synchrony in spring between oak and powdery mildew was shown to be an important factor explaining the severity of the disease (Marçais et al. 2009; Desprez-Loustau et al. 2010). However, both fungus and tree exhibit a polycyclic development within a season. Primary infections can give rise to secondary infections and so forth, resulting in a potentially exponential increase of the fungal population. Reciprocally, $Q$. robur presents a rhythmic growth (also called polycyclism) expressed as several flushes of shoot growth within one growing season, especially in the young age (Barnola et al. 1990; Collet et al. 1997). The interplay between oak growth patterns and susceptibility to the disease (Edwards and Ayres 1982) may therefore determine both host and parasite performances.

The objective of our study was to assess disease-induced phenotypic changes in oak seedlings including not only expected negative effects on fitness but also modifications with potential adaptive value for the tree and the pathogen. We addressed the specific following questions: (i) How much is height growth, considered as a good proxy of fitness (Sage et al. 2011), affected by infection in oak seedlings? (ii) Are there infection-induced qualitative changes in oak growth, especially in the timing of flushes within and between years? (iii) Do alterations in tree growth patterns benefit the plant and/or the pathogen?

\section{Materials and methods}

\subsection{Plant material}

Ideally, assessing the effect of infection on a variety of traits would require the comparison of the same genotypes under different infection levels, in order to separate effects of infection on a specific trait from inherent differences between genotypes for that trait, which would favour or prevent infection (Pan and Clay 2003; Baucom and de Roode 2011). In the absence of available vegetatively propagated oak clones, the genetic replicates assayed in the different infection environments were 15 half-sib families, each represented by numerous individuals. Acorns were collected in the autumn of 2008 under 15 isolated mature $Q$. robur trees (i.e. with nonoverlapping canopies with their neighbours) at Pierroton,

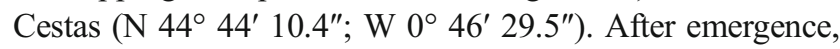
all seedlings and putative maternal parent trees were genotyped using a set of nine microsatellite markers (Guichoux et al. 2011). A few seedlings harbouring alleles not found in their expected mother tree were discarded from the analyses.

\subsection{Experimental design}

The design was set up at the INRA experimental domain in Pierroton, in a clearing surrounded by pine trees (Pinus pinaster Ait.) and broadleaved species (especially $Q$. robur). The experimental site was fenced to prevent grazing by mammalian herbivores. Little damage from abiotic and biotic (fungi, insects) factors other than powdery mildew was observed throughout the experiment (estimated at less than $5 \%$ of leaf surface area). The herbaceous plants growing between plots were removed by mowing, twice a year. Little weed development occurred within plots.

The design included nine unit plots corresponding to three levels of parasite exposure randomly distributed within three 
spatial blocks. Plots were separated by a distance of $4 \mathrm{~m}$. Acorns were sown on 21-27 April 2009 at a $10 \mathrm{~cm} \times 10 \mathrm{~cm}$ distance in each unit plot, in eight rows of 38 plants. Acorns from the different families were randomly distributed within and between plots, with 173 acorns per family on average ( minimum $=118$; maximum $=285$ ). Each unit plot was surrounded by a guard row with acorns from a bulk provenance.

The three parasite levels were obtained as follows. The "low" parasite level was obtained by repeated fungicide applications. Myclobutanil was chosen for its efficacy against powdery mildew. It is one of the very few fungicides with an authorized usage for forest trees in France (http://e-phy. agriculture.gouv.fr/). Contrary to some other triazole fungicides showing plant-growth regulator effects, it was not shown to have non-target effects on growth and drought tolerance in a few studied tree species (Rosenberg et al. 2003; Percival and Noviss 2008). In 2009, the first application was done on 22 June. Six applications were done during the whole season (weeks 25, 28, 30, 32, 35, 37). The same number of applications was done in 2010, starting on 1 June (weeks 22, 27, 30, 31, 34, 39-the low frequency at the beginning of the season was due to a rainy period). In order to achieve better control, the frequency of applications in early spring was increased in 2011 (first on 27 May, weeks 21, 23, 25, 27, 30, 31, 33, 35, 39). The "medium" parasite level corresponded to natural infection. The "high" level was obtained by providing extra-inoculum to the seedlings in the ad hoc plots. This was achieved by blowing spores from highly sporulating leaves above the seedlings, using a portable air compression device. Sporulating leaves were produced in the laboratory by inoculating young oak seedlings of a bulk provenance of $Q$. robur with inoculum originating from an initial population of local powdery mildew (naturally infected leaves collected in the summer of 2008 around the experimental site) which was maintained by successive re-inoculations until the spring of 2009 and thereafter. In order to obtain a homogeneous and targeted distribution of inoculum, a plastic tower was used as inoculation box and moved along the row. Inoculations were performed on 19 June 2009, 11 May and 24 June 2010, and 20 and 28 April 2011.

\subsection{Monitoring of oak growth}

A fine monitoring of seedlings was realised during the three growing seasons following sowing, i.e. in 2009, 2010 and 2011. Seedling emergence from acorns occurred mostly within a few weeks following sowing in April 2009, reaching 50\% for the whole design after 1 month. The emergence rate slightly increased thereafter, reaching $67 \%$ at the end of the first growing season. We checked that no differences in the dynamics of seedling emergence occurred between plots that were subsequently subjected to different parasite exposure levels. Each oak family was eventually represented by $37 \pm$ 17 (mean \pm standard deviation) seedlings in each parasite exposure treatment.

Timing of growth flushes was monitored in 2010 and 2011. Phenology of budburst was monitored by weekly assessment in April-May (4-5 dates each year, between weeks 15 and 20 in 2010, 15 and 18 in 2011). At each date, a phenological score was given to each seedling using a 5 -grade scale: $0=$ dormant bud; $1=$ leaves emerging from the bud scales; $2=$ leaves and shoots starting to develop; $3=$ leaves with final size but still tender and light green; and $4=$ fully developed leaves, dark green (assessed on the leading shoot). The annual budburst precocity index was calculated for each seedling as the mean phenological score over the different dates in a year. The occurrence of a second growth flush from the apical bud on the leading axis was noted on 15 June in 2010 and on 24 May in 2011. The occurrence of a third flush was noted on 20 June in 2011.

The total number of flushes (which can be determined a posteriori from morphological features) was assessed at the end of the growing season in all 3 years, as well as annual shoot elongation of the dominant terminal axis and plant height (Figure S1).

Changes in apical dominance were frequently observed during the 3-year monitoring of the seedlings. In the spring of 2010, budburst failure of apical buds, often associated with terminal shoot necrosis, was frequently observed and resulted in the development of a new leader shoot from a lower bud in affected seedlings. Apical bud mortality was recorded for each seedling as a binary variable (yes/no). Other changes in dominance were not recorded systematically, but an index of height growth efficiency (HGE) was defined to capture some part of this phenomenon. HGE was calculated as the ratio of height increment to terminal shoot elongation in the same year, as follows (Figure S1):

HGEn $=(\mathrm{Hn}-\mathrm{Hn}-1) / \mathrm{Ln}$,

with HGEn=height growth efficiency in year $n$; $\mathrm{Hn}=$ final height in year $n ; \mathrm{Hn}-1=$ final height in year $n-1$; and $\mathrm{Ln}=$ total leader shoot elongation in year $n$.

If a strict apical dominance is maintained, then annual height increment will be equal to leading shoot elongation and HGE will be equal to 1 . In contrast, changes in leading axes, caused by apical mortality or other changes of apical dominance, will lead to HGE values lower than 1.

\subsection{Infection assessments}

Infection was assessed by trained observers as a percentage of leaf area covered by mycelium for the whole seedling. 
Assessment of infection on the first flush, when leaves were fully developed and before the development of any second flush, was completed on 9 June 2009, 15 June 2010 and 24 May 2011. The final assessment, taking into account all flushes, was on 15 October 2009, 29 September 2010 and 27 July 2011. Monitoring was stopped earlier in 2010 and even more in 2011 because of higher infection levels resulting in defoliation in the second flush.

The percentage of leaf area covered by mycelium is primarily a host-related measurement of infection. In order to obtain a parasite-related measurement of infection success, we calculated a correlate of spore production (SPOR) per seedling. Assuming a constant production of spores per unit of leaf area infected, the number of spores produced per seedling can be calculated as the product of the percentage of leaf infection by the total leaf area. Since total leaf area could not be measured for each seedling, we used seedling basal area (SBA), the cross-sectional area of the stem, as a correlate. The allometric relationship between stem basal area and whole-tree leaf area has long been recognized (McDowell et al. 2002). SPOR was then calculated as follows:

$\mathrm{SPOR}=\%$ LAInf $\times$ SBA,

assuming that $\mathrm{SBA}=k \times \mathrm{LA}$

with \%LAInf=mean percentage of leaf area infected over 3 years (final assessments); SBA= seedling basal area, calculated from diameter measured at $2 \mathrm{~cm}$ above collar level in March 2011; LA=seedling leaf area; and $k=$ (non-estimated) proportionality coefficient.

\subsection{Statistical analyses}

All statistical analyses were performed with SAS 9.2 software (SAS Institute Inc. 2011).

The response (dependent) variables of the models were first foliar infection (to check that exposure to different parasite levels indeed resulted in contrasting levels of infection) and then phenotypic variables related to oak growth and potentially affected by parasite exposure/infection: precocity index, shoot elongation, height, etc. The independent (explanatory) factors were block (3 levels), family (15 levels), parasite and its interaction with family. The parasite effect was first tested by including "exposure" as a categorical variable in the model, with three levels corresponding to the three treatments in the experimental design. Secondly, since infection was likely to vary within the same exposure level, the same models were ran with adding infection as a quantitative covariate ( 1 degree of freedom) and its interaction with family. The family-byparasite (exposure and infection) interaction effect was included to test the generality of parasite effects across families. All factors were treated as fixed effects. Quantitative variables were analysed with a general linear model with the sum of squares for a given effect calculated with all other variables included in the model (type III sum of squares). The distribution of residuals was analysed (by plots, summary statistics and tests with the univariate procedure of SAS) in order to check that it did not depart too far from the assumptions of normality and homogeneity of variances required for the validity of $F$ tests. Due to the unbalanced design, least square means (predicted population margins) were computed for comparisons between levels of parasite exposure, with pairwise differences tested with a $t$ test. All means referred to thereafter correspond to the marginal means. For the analysis of variables expressed as binary data, such as occurrence of a second flush or apical bud mortality, a logistic regression model was used and the effects of independent variables (block, family, parasite and interactions, as before) were tested with a Wald chi-square test. The odds ratios and their corresponding $95 \%$ Wald confidence intervals were computed to compare the effects of different parasite levels. When the family-by-parasite effect was not significant, a single value of odds ratio for each comparison between parasite levels was computed across families by omitting the interaction in the model. The Akaike information criterium (AIC) was used for the comparison of models with or without infection included as a quantitative variable.

\section{Results}

\subsection{Infection levels}

The low-medium-high parasite exposures indeed resulted in different levels of powdery mildew infection (Table 1). Infection levels on the first flush were quite low on average, with less than $10 \%$ leaf area infected, except in 2011 for the high level. An increasing trend of infection with parasite exposure was observed, from approximately $2 \%$ of leaf area infected over the 3 years in the low level, to $5 \%$ in the medium level and $11 \%$ in the high level (Table 1). The parasite exposure effect was significant in 2010 and $2011\left(F_{2,1611}=\right.$ 13.69 and $F_{2,1605}=614.00 ; P<0.0001$ ), discriminating the three levels from each other (the effect was not significant in 2009 as expected since fungicide applications and inoculations had not yet started at the time of the first flush). Final (maximal) infection remained low in the low treatment (12\%) and was quite high in the medium and high treatments ( 31 and $40 \%$ on average over the 3 years, respectively) (Table 1). Differences were highly significant for final infection in all 3 years, discriminating the three levels of parasite exposure $\left(F_{2,1614}=53.59 ; F_{2,1600}=258.65\right.$; and $F_{2,1599}=1471.89$ respectively in 2009, 2010 and 2011 $-P<0.0001$ ). A significant family effect was observed for all assessments but no significant interaction of family-by-parasite level was observed in 2009 and 2010. The significant interactions in 2011 for both 
Table 1 Percentage of leaf area infected in the low-medium-high parasite treatments

\begin{tabular}{lll}
\hline $\begin{array}{l}\text { Parasite } \\
\text { treatment }\end{array}$ & $\begin{array}{l}\text { Early season infection } \\
\text { first flush) }^{\mathrm{a}}\end{array}$ & $\begin{array}{l}\text { Final infection } \\
\text { (all flushes) }^{\mathrm{b}}\end{array}$ \\
\hline Low (L) & $1.7(4.0-0.7-0.5)$ & $12.4(14.1-18.6-4.5)$ \\
Medium (M) & $4.8(3.4-1.4-9.7)$ & $31.2(23.1-30.5-39.9)$ \\
High (H) & $10.7(3.7-2.4-26.1)$ & $39.9(25.9-35.8-57.9)$ \\
\hline
\end{tabular}

Figures in italics are the marginal means over 3 years (2009-2010-2011)

${ }^{a}$ Assessed on 9 June, 17 May and 4 May in 2009, 2010 and 2011, respectively

${ }^{\mathrm{b}}$ Assessed on 15 October 2009, 29 September 2010 and 27 July 2011

early and late infection were linked to differences in the intensity (slope) of the increasing trend of infection from low to medium and high, but the ranking of families was highly conserved (not shown).

3.2 Effects of parasite exposure/infection on shoot elongation and height

Parasite level had a significant effect on growth as soon as the first year (Fig. 1): the height loss at the end of 2009 in medium and high parasite exposures were $14 \%$ on average when compared to low (adjusted mean height $=16.3 \mathrm{~cm}$ in low; $14.0 \mathrm{~cm}$ in medium; and $14.0 \mathrm{~cm}$ in high) $\left(F_{2,1618}=21.69\right.$; $P<0.0001)$.

Growth was increasingly affected in 2010 and 2011. Annual shoot elongation (including all flushes) was decreased in the medium parasite exposure compared to low by $23 \%$ in 2010 (14.8 vs. $19.3 \mathrm{~cm})$ and $34 \%$ in 2011 (7.9 vs. $11.8 \mathrm{~cm})$. Relative decreases in the high parasite exposure were $28 \%$ in $2010(14.0 \mathrm{~cm})$ and $20 \%$ in $2011(9.5 \mathrm{~cm})\left(F_{2,1603}=54.30\right.$; $P<0.0001$ in $2010 ; F_{2,1598}=43.07 ; P<0.0001$ in 2011).

Height increments were even more affected by parasite level than shoot elongation. Height increment loss in

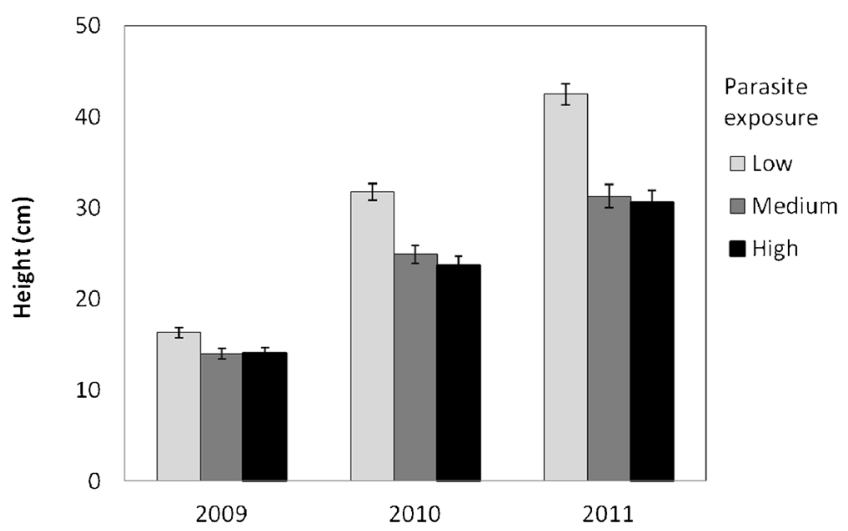

Fig. 1 Marginal means (with confidence intervals at 95\%) of seedling height at the end of the 2009, 2010 and 2011 growing seasons for three levels of oak powdery mildew exposure comparison to the low parasite exposure reached 29 and $38 \%$ in 2010 and 43 and $36 \%$ in 2011, in the medium and high levels, respectively. The corresponding height growth efficiencies (HGE) decreased with increasing parasite level: $\mathrm{HGE}=0.78-0.69-0.65$ in 2010, 0.88-0.65-0.66 in 2011, for the low-medium-high levels, respectively $\left(F_{2,1601}=14.33\right.$, $P<0.0001$ in $2010 ; F_{2,1597}=19.85, P<0.0001$ in 2011).

Finally, height loss after 3 years was $26 \%$ for the medium parasite exposure compared to the low level (31.2 vs. $42.5 \mathrm{~cm}$ ) (Fig. 1). Height was only very slightly more affected in the high parasite level $(-28 \%, 30.5 \mathrm{~cm})$. The parasite level effect was highly significant $\left(F_{2,1599}=116.56 ; P<0.0001\right)$ and discriminated the low from the medium and high levels but medium and high were not statistically different. The family effect was highly significant $\left(F_{2,1599}=13.90 ; P<0.0001\right)$ but the same effect of decreasing height with increasing parasite exposure/infection was observed for all families (Fig. 2), as expressed by the non-significant family-by-parasite exposure interaction $\left(F_{28,1599}=1.09 ; P=0.3421\right)$. When infection (mean of final infection in 2009, 2010 and 2011) was added as a covariate, parasite exposure and family effects remained significant in addition to the infection effect $\left(F_{1,1584}=12.89\right.$; $P=0.003)$. Neither parasite-by-family nor infection-by-family interactions were significant $\left(F_{28,1584}=1.05, P=0.4001\right.$ and $F_{14,1584}=1.34, P=0.1768$, respectively).

\subsection{Precocity of spring budburst and apical bud mortality during winter}

Budburst was slightly earlier in seedlings exposed to high parasite levels, in 2010 and 2011. Precocity indices were $1.87,1.87$ and 1.93 in 2010 and 2.36, 2.43 and 2.50 in 2011, for the low, medium and high treatments, respectively. The effect of parasite level was only significant in 2011 (2010, $\left.F_{2,1612}=2.91, P=0.0547 ; 2011, F_{2,1605}=18.54, P<0.0001\right)$. The family effect was highly significant in both years

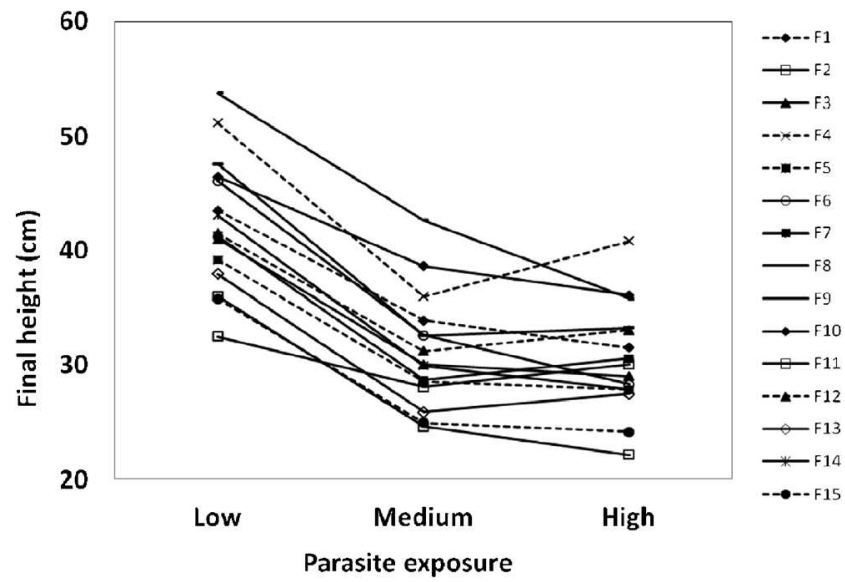

Fig. 2 Marginal means of seedling height at the end of the 2009, 2010 and 2011 growing seasons for 15 oak families exposed to three levels of powdery mildew 
$\left(F_{14,1612}=60.50\right.$ and $\left.F_{14,1605}=68.71 ; P<0.0001\right)$. Earlier budburst in higher levels of parasite exposure was observed for 13 out of 15 families in 2011. The interaction of parasite level and family was statistically significant $\left(F_{28,1605}=1.77\right.$; $P<0.0079)$, mainly showing differences in the intensity of the response (not shown). No effect of the infection covariate (final infection in the preceding year) nor of its interaction with family were significant in both years.

A high frequency of budburst failure on the terminal shoot was observed in the spring of 2010. Apical bud mortality during winter affected almost one third of all seedlings in the low (33\%) and medium (32\%) parasite levels; the frequency was even higher ( $43 \%)$ in the high level. The logistic regression showed a significant effect of block, family and parasite level, with no significant parasite-by-family interaction on the occurrence of apical bud mortality. Only the high parasite level was differentiated from the two others with odds ratio estimates of 1.60 (confidence interval $=1.24-2.07$ ) and 1.61 (1.24-2.10) for high against low and high against medium, respectively, corresponding to a relative increase of $60 \%$ in the odds of apical mortality between the high and the low and medium parasite exposure levels. The model was slightly improved (AIC reduced from 2,044 to 1,884) by adding an infection effect (final infection in the preceding year, i.e. 2009). The infection effect had an odds ratio of 1.04 (confidence interval $=1.033-1.047$ ), indicating a $4 \%$ increase in the odds of apical mortality for each $1 \%$ increase in the percentage of infection, in addition to the effects included in parasite exposure level (odds ratio for high against low and high against medium maintained at values greater than 1, 1.03 and 1.53 , respectively).

\subsection{Timing and number of growth flushes}

In 2010, no difference in the timing of the second flush could be detected between treatments. On 15 June, a very high proportion of nearly $90 \%$ seedlings had started their second flush in the low, medium and high parasite treatments. In contrast, a second flush occurred much earlier in the high parasite level in 2011 than in the low and medium levels. On 24 May, a second flush was visible in $80 \%$ of seedlings in the high level as opposed to only 45 and $31 \%$ of seedlings in the medium and low levels, respectively. The logistic model for the occurrence of the second flush on 24 May 2011 showed a significant effect of parasite level, in addition to family and block effects, with no significant parasite-by-family interaction (Table 2). The parasite level effect was maintained, and odds ratio estimates were little affected when the budburst precocity index was added as an additional explaining variable. Very high odds ratio estimates were obtained when comparing parasite levels. A nearly twofold increase in the odds of having the second flush was observed for seedlings exposed to the medium parasite level compared to those in the low level. Odds increased to fivefold for the high vs. medium parasite level comparison (Table 2). Adding infection on the first flush as an explaining variable, in addition to parasite exposure, did not affect the results. Similarly, at the June assessment in 2011, $13 \%$ of seedlings in the high parasite level had a third flush compared to almost none ( 0.6 and $0.2 \%$ ) in the medium and low levels, respectively. Finally, at the end of the season, an increasing number of flushes were observed from the low to the medium and high parasite levels, with adjusted means of 2.85, 3.04 and 3.17 in 2010 and 2.07, 2.34 and 2.64 in 2011, for the low, medium and high parasite levels, respectively. Both logistic models for the probability of a third flush assessed in October 2010 or in October 2011 showed a significant effect of parasite level, in addition to the block and family effects, with no significant parasite-byfamily interaction (Table 3). The parasite level effect remained highly significant, and the odds ratio estimates were little affected when lengths of the first and second flushes and precocity of budburst were added as additional explaining variables to the simplest model (not shown). Odds ratio estimates were very high for the parasite exposure effect, especially in 2011, with an estimate of 13.2 for the high vs. low level (Table 3). Adding infection as an explaining variable only marginally improved the model and slightly affected the results (not shown).

After 3 years, seedlings in the low parasite exposure had produced 7.2 shoot flushes on average, 7.5 in the medium exposure and 8.0 in the high parasite level (Fig. 3). The parasite level effect was highly significant $\left(F_{2,1556}=63.68\right.$; $P<0.0001)$ and so was the family effect $\left(F_{14,1556}=8.5\right.$; $P<0.0001)$. No significant family-by-parasite interaction was observed $\left(F_{28,1556}=1.29 ; P=0.0797\right)$ (Fig. 3$)$. When mean infection (final assessment) over the 3 years was added as a covariate, the effect was highly significant $\left(F_{1,1541}=\right.$ $30.72 ; P<0.0001)$ in addition to all previous significant effects, but the infection-by-family interaction was not $\left(F_{14,1541}=0.93 ; P=0.5254\right)$.

3.5 Relationship between oak growth polycyclism and host and parasite performances

Within each parasite level, a general positive relationship was observed between the number of growth flushes and height at the end of the three growing seasons (Fig. 4). Comparisons across parasite levels could only be made at seven and eight flushes, where all families were represented $(11 \pm 6$ seedlings per family, parasite level and number of flushes). In order to assess the potential benefit of one additional flush in infected plants, we compared differences in heights, adjusted to family and block, between the low and high parasite levels either at seven flushes for both levels (giving 41.4 and $26.6 \mathrm{~cm}$, respectively) or at seven flushes for low and eight flushes for high (41.4 and $31.4 \mathrm{~cm}$, respectively) (Fig. 4). We considered 
Table 2 Results of the logistic model of occurrence of a second flush on 24 May 2011. The precocity index refers to the first flush and was calculated as the mean phenological score of leaf phenology assessed at four dates from 12 April to 4 May

\begin{tabular}{|c|c|c|c|c|}
\hline \multirow[t]{2}{*}{ Effect } & \multicolumn{2}{|c|}{ Model without precocity index } & \multicolumn{2}{|c|}{ Model with precocity index } \\
\hline & $\begin{array}{l}\text { Wald chi-square } \\
\text { (probability) }\end{array}$ & $\begin{array}{l}\text { Odds ratio estimates } \\
\text { (confidence interval) }\end{array}$ & $\begin{array}{l}\text { Wald chi-square } \\
\text { (probability) }\end{array}$ & $\begin{array}{l}\text { Odds ratio estimates } \\
\text { (confidence interval) }\end{array}$ \\
\hline Parasite level & $251.2(<0.0001)$ & & $227.5(<0.0001)$ & \\
\hline Medium vs. low & & $1.9(1.5-2.5)$ & & $1.8(1.4-2.3)$ \\
\hline High vs. medium & & $5.3(4.0-7.0)$ & & $5.1(3.8-6.8)$ \\
\hline High vs. low & & $10.0(7.5-13.4)$ & & $9.1(6.8-12.2)$ \\
\hline $\begin{array}{l}\text { Block } \\
\text { ( } 2 d f, 3 \text { comparisons) }\end{array}$ & $14.7(0.0006)$ & $0.6-0.7-0.9$ & $12.0(0.0025)$ & $0.6-0.7-0.8$ \\
\hline $\begin{array}{l}\text { Family } \\
(14 d f, 105 \text { comparisons })^{\mathrm{a}}\end{array}$ & $102.5(<0.0001)$ & $0.1-1.0-6.5$ & $93.9(<0.0001)$ & $0.1-0.9-6.4$ \\
\hline Precocity index & & & $22.6(<0.0001)$ & $2.7(1.7-3.5)$ \\
\hline
\end{tabular}

${ }^{\text {a }}$ Only the minimum, median and maximum values of the 105 odds ratio estimates are given

that the former difference gave an estimate of theoretical height loss caused by infection without growth compensation provided by one additional flush, while the latter was close to actual loss taking into account compensatory growth. The additional flush was then estimated to provide a $34.2 \%$ compensation of theoretical height loss over the 3 years.

However, additional flushing was not beneficial in all years. The frequency of apical bud mortality observed in the early spring of 2010 increased significantly with the number of growth flushes during the 2009 growing season (Fig. 5; significant Wald test for the number of flushes introduced as a covariate in the logistic regression of apical bud mortality with block, family, and parasite factors - not shown). The mortality rate almost doubled, from approximately 0.3 to 0.6 , between seedlings with two or three flushes (representing together $92 \%$ of all plants), whatever the parasite exposure (Fig. 5no significant interaction between parasite exposure and number of flushes).
On the other hand, polycyclism was also positively related to powdery mildew performance, estimated by spore production (SPOR), in all three parasite levels (Fig. 6; significant effect for the number of flushes introduced as a covariate in the linear model of SPOR with block, family and parasite factors; no significant interaction with parasite exposurenot shown). One additional flush was associated with a significant increase in SPOR, e.g. $+39,+20$ and $+15 \%$ between seven and eight flushes, for the low, medium and high parasite levels, respectively.

\section{Discussion}

4.1 Demonstration of infection effects on seedling phenotypes Important differences in growth, both quantitative and qualitative, were observed in oak seedlings exposed to different

Table 3 Logistic model of the occurrence of a third flush in 2010 and 2011

\begin{tabular}{|c|c|c|c|c|}
\hline & \multicolumn{2}{|l|}{2010} & \multicolumn{2}{|l|}{2011} \\
\hline & $\begin{array}{l}\text { Wald test } \\
\text { (probability) }\end{array}$ & $\begin{array}{l}\text { Odds ratio estimate } \\
\text { (confidence interval) }\end{array}$ & $\begin{array}{l}\text { Wald test } \\
\text { (probability) }\end{array}$ & $\begin{array}{l}\text { Odds ratio estimate } \\
\text { (confidence interval) }\end{array}$ \\
\hline $\begin{array}{l}\text { Block } \\
\text { ( } 2 d f, 3 \text { comparisons })\end{array}$ & $12.6(0.0018)$ & $0.6-0.7-0.8$ & $281.3(<0.0001)$ & $0.4-0.5-0.7$ \\
\hline $\begin{array}{l}\text { Family } \\
\quad(14 d f, 105 \text { comparisons })^{\mathrm{a}}\end{array}$ & $32.2(0.0037)$ & $0.2-0.8-4.4$ & $42.1(0.0001)$ & $0.2-1.1-6.1$ \\
\hline Parasite level & $40.4(<0.0001)$ & & $51.0(<0.0001)$ & \\
\hline Medium vs. low & & $1.7(1.2-2.4)$ & & $4.6(3.4-6.2)$ \\
\hline High vs. medium & & $1.7(1.3-2.3)$ & & $2.9(2.2-3.7)$ \\
\hline High vs. low & & $2.8(2.0-3.9)$ & & $13.2(9.7-17.8)$ \\
\hline
\end{tabular}

${ }^{\text {a }}$ Only the minimum, median and maximum values of the 105 odds ratio estimates are given 


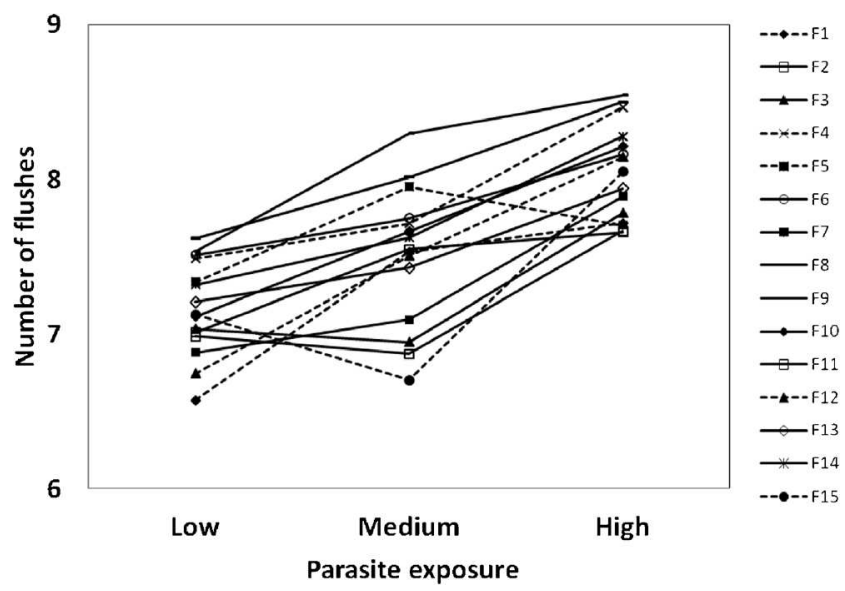

Fig. 3 Marginal means of the total number of flushes per seedling during the 2009, 2010 and 2011 growing seasons for 15 oak families exposed to three levels of powdery mildew

powdery mildew pressures. These are very likely a result of infection, and not simple correlates, since the same genetic entities were compared under the three parasite exposures, in order to decouple infection effects from genetic effects. The only way to achieve a low parasite level in the field was to protect seedlings by using fungicides. Non-target effects of myclobutanil, e.g. on ectomycorrhizal fungi, cannot be discarded (Desprez-Loustau et al. 1992). However, the fact that most studied variables were affected not only between the low (i.e. fungicide treated) and medium parasite levels but also between medium and high strongly suggests that changes in the host can be explained by increased parasite burden. Significant differences between families were observed for most studied variables, reflecting differences in resistance/ susceptibility to infection and in initial vigour. However, interactions between the family effect and the parasite effect were in most cases not significant. Most observed changes may therefore be considered as a general response to infection in different genetic backgrounds of $Q$. robur.

\subsection{Negative effects of infection on seedling height growth}

The most expected change related to infection was growth reduction, affecting current shoot elongation and ultimately

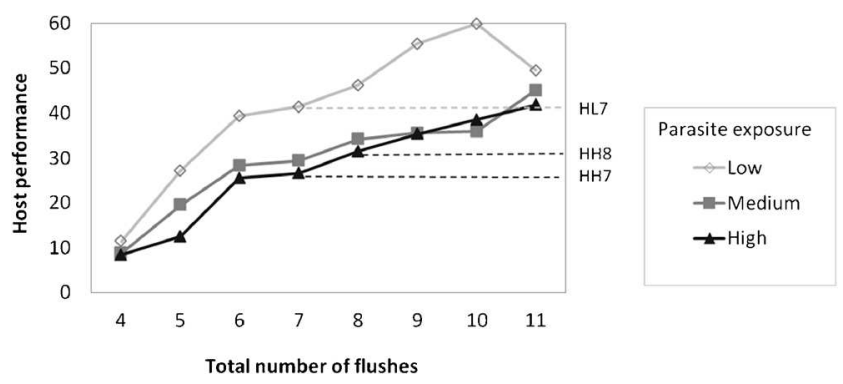

Fig. 4 Relationship between polycyclism (total number of flushes over 3 years) and host performance in the three parasite exposure levels. Height (in centimetres) was used as a proxy of plant performance

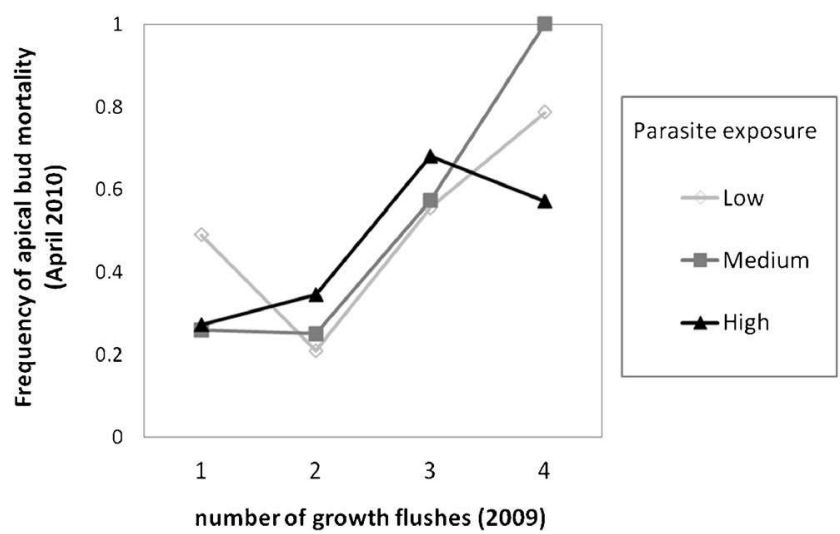

Fig. 5 Relationship between number of flushes in 2009 and apical bud mortality observed in the early spring of 2010 in the three parasite exposure levels

plant height. Since its first recorded outbreaks in Europe in the early twentieth century, powdery mildew has been considered as a major factor potentially limiting the success of oak regenerations, by strongly affecting seedling growth and ultimately survival (Jarvis 1964; Marçais and Desprez-Loustau 2013). However, quantitative estimates of these effects are rare (Pap et al. 2012). Our results showed a sharp decrease in height $(-26 \%)$ from low to medium parasite level, almost proportional to the percentage of leaf area infected (12 and $31 \%$, respectively). Increasing infection from the medium to high exposure (resulting in $40 \%$ final leaf area infected) had no further visible effect. Very low mortality (less than $1 \%$ data not shown) was observed within the time frame of the study, which could not be related to powdery mildew infection. This may be explained by much more favourable conditions in our experimental site than in a natural regeneration, probably due to the low herbaceous (and between seedling) competition and protection against grazing.

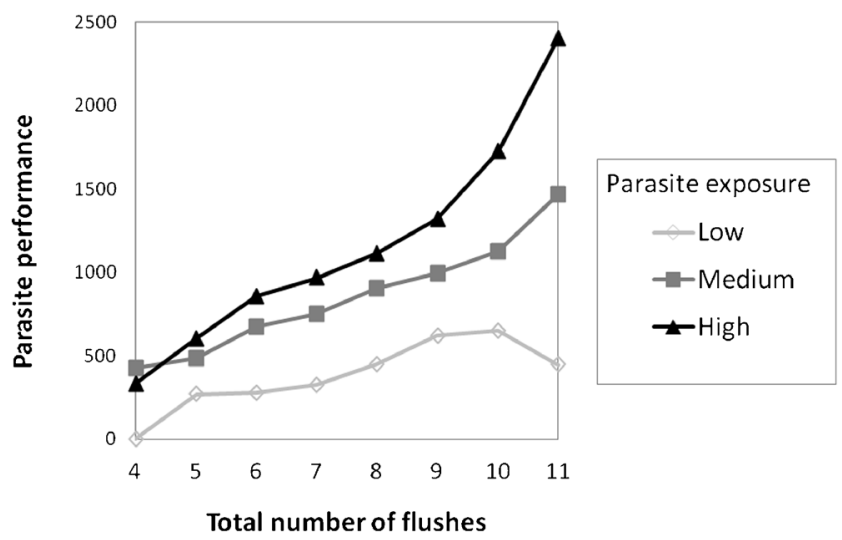

Fig. 6 Relationship between polycyclism (total number of flushes over 3 years) and parasite performance in the three parasite exposure levels. Parasite performance was assessed by a correlate of spore production (SPOR) calculated as the product of the mean percentage of leaf area infected per seedling over the 3 years (\%LAInf) by the seedling basal area (SBA) in the spring of 2011 , used as a correlate of leaf area $(\mathrm{SPOR}=\% \mathrm{LAInf} \times \mathrm{SBA})$ 


\subsection{Infection-related changes in growth patterns}

A striking result of our study is the alteration in growth flush patterns in the different parasite environments. High (and to a lesser degree, medium) parasite exposure was associated with an accelerated shoot flushing both between and within years. This was expressed as slightly earlier budburst, followed by earlier second flushing (not only as a consequence of earlier budburst but with an amplified effect of parasite exposure), and ultimately higher number of shoot flushes at the end of the season, compared to the low parasite exposure. Polycyclism in trees has usually been associated with high resource availability and plant vigour (Collet et al. 1997; Collin et al. 1996). The production of the second flush was shown to be a strong carbon sink, supported by recently assimilated photosynthates from first-flush source leaf tissues (Harmer 1992; Lockhart et al. 2003). It was therefore unexpected to observe more polycyclism in seedlings experiencing a biotic stress characterized by the consumption of host photosynthates by the parasite (Hewitt and Ayres 1976; Hajji et al. 2009). A positive effect of parasite infection on tree growth polycyclism has not been previously described for oak powdery mildew, or for any other disease, to our knowledge. Mizumachi et al. (2006) reported an increased probability of subsequent flushes as a result of insect leaf damage on the parent shoot growth unit, which may be similar to what we observed. However, polycyclism differs from the regeneratory or compensatory growth reported in most studies dealing with herbivores. Contrary to powdery mildew infection, which does not induce leaf loss (at least in the first flush - cf. Marçais and Desprez-Loustau 2013), herbivory damage is often mostly characterized by tissue loss. In most cases, new growth in response to leaf tissue loss is based on increased lateral branching caused by a release of apical dominance and the activation of dormant meristems (Gruntman and Novoplansky 2011). Nevertheless, increased branching following herbivory damage was suggested to be an adaptive plastic response of the plant to internal and environmental signals, and not simply a passive outcome of damage (Gruntman and Novoplansky 2011). Direct effects of infection through internal signals linked to the host-pathogen interaction are also strongly suggested in our experimental conditions. An alternative hypothesis for lower polycyclism in the low parasite level could involve increased resource competition between seedlings, especially in 2011. However, crowns were not yet overlapping. Moreover, shoot elongation in 2011 was higher in the low compared to the high parasite level for both the first and second flushes (3.4 vs. $2.1 \mathrm{~cm}$ and 7.9 vs. $6.0 \mathrm{~cm}$, respectively). Competitionmediated stress in the low parasite level is thus unlikely, and the direct effect of infection on growth patterns (polycyclism) remains the most probable explanation of observed changes.
4.4 Host tolerance response or manipulation of host physiology by the parasite?

Phenotypic changes in infected hosts have often been categorized in three distinct phenomena, according to their origin and consequences: secondary outcomes of infection with no adaptive value, host adaptations that reduce the detrimental consequences of infection and parasitic adaptations that facilitate transmission (Shykoff and Kaltz 1998). Decreased oak growth is likely a direct consequence of nutrient uptake by the parasite. Conversely, other changes observed in growth patterns, especially increased polycyclism, are not expected to be a passive outcome of infection since a reverse pattern would be predicted. Polycyclism has often been observed as a plastic response to high resource availability (Collet et al. 1997). Acquisition of host resources by the parasite should theoretically decrease the carbon source of currently growing shoots and thus the probability of an additional flush. Increased polycyclism might then be viewed as an infection-induced active response, either as part of a tolerance response from infected seedlings or as a manipulation by the parasite. The origin (molecular, biochemical and physiological mechanisms) of the changes observed in infected plants was out of the scope of our experiment. However, it is known that the intra-cellular haustorium of powdery mildew is an active interface allowing actively regulated exchanges of molecules between host and parasite in both directions (Panstruga and Dodds 2009). With regard to the adaptive value of the changes, either for plant or pathogen, our results suggest that the benefit of polycyclism could be shared between the two partners, since both plant and pathogen fitness-related variables increased with an increasing number of annual growth flushes. From the plant's perspective, polycyclism was positively related with height, as previously observed (Collet et al. 1997). It might therefore enhance seedling competitive ability, especially through improved light interception and overtopping of neighbours (Sage et al. 2011). Increased polycyclism in the high parasite exposure provided a partial compensation to parasite damage by limiting height loss and can then be viewed as a tolerance mechanism of trees to infection. Interestingly, all 15 families showed very similar responses of height and number of flushes to the different levels of parasite exposure/infection (as expressed by non-significant parasite-by-family interactions). The norm of reaction of plant fitness over a range of infection levels is often used to estimate plant tolerance (Baucom and de Roode 2011). Our results therefore suggest low variation across families (thus likely low genetic variation) for tolerance, although families were different in resistance sensu stricto (expressed as a significant effect of family on infection). These findings are consistent with the theoretical prediction that resistance traits tend to be polymorphic while tolerance traits tend to be fixed within populations (Roy and Kirchner 2000). However, increasing the number of flushes in a season is costly and may 
not be beneficial for the plant on a longer term. Analyses of apical bud mortality in early 2010 strongly suggested that increased polycyclism exposed seedlings to greater winter damage. The low overwintering viability of second flushes, especially in interaction with powdery mildew infection, had already been reported (Harmer 1992). This was explained by lower cold hardiness (Anekonda et al. 1998; Marçais and Desprez-Loustau 2013). The net benefit of additional flushes for the tree will then depend on environmental factors, especially winter temperatures. Furthermore, recurrent flushing provides a longer availability of receptive tissues for the parasite as the season progresses, at a time when powdery mildew inoculum has built up from initial infections on the first flush. Unlike new flushing in response to herbivory, which may be a mean to produce functional leaves that will escape the enemy, here the second and subsequent flushes are exposed to increasing propagule pressure due to the polycyclic life cycle of the pathogen. Shoots of the second and subsequent flushes have been repeatedly reported as more severely infected than the first flush shoots (Harmer 1992; Marçais and Desprez-Loustau 2013). We indeed observed a positive relationship between number of shoot flushes and spore production per seedling. Increased polycyclism thus provided an amplification of the fungus population, probably leading to a higher probability of survival in the following year, and thus improved parasite fitness.

Finally, our study highlights that the effect of parasites in the expression of plant phenotypic traits, such as phenology and ultimately plant architecture, may well have been underestimated. Plastic traits such as phenology are commonly viewed as the expression of the interaction of plant genes with abiotic environment (Collet et al. 1997; Chuine and Cour 1999). Here, we show that deep alterations in oak phenotypes can occur in response to parasite exposure. These changes were likely, in part, the expression of a plant response providing a compensation for parasite-induced damage, hence tolerance to infection. This defence strategy has often been neglected in breeding programmes but tolerance traits might be an interesting component of durable disease control. However, our results show that the parasite exploited the host response by increasing its own performance (Lefevre et al. 2008). Finally, our findings are consistent with the increased recognition of the complex interplay between defence responses and plant development (Alcázar et al. 2011).

\begin{abstract}
Acknowledgments The authors are very grateful to the Unité expérimentale Forêt Pierroton, UE 0570, INRA, especially Frédéric Bernier, Henri Bignalet and Luc Puzos for their important contribution to the installation and monitoring of the field experiment. This study benefitted from an ANR Grant ANR-07-GPLA-010, the REALTIME project, and was supported by INRA. Cécile Dantec had a PhD grant from INRA and the Aquitaine Region. Projet PHENOLOGIE : Phénologie et stratégies temporelles : adaptation des populations au changement climatique
\end{abstract}

Data availability Data will be made available upon request.

\section{References}

Alcázar R, Reymond M, Schmitz G, de Meaux J (2011) Genetic and evolutionary perspectives on the interplay between plant immunity and development. Curr Opin Plant Biol 14:378-384

Anekonda TS, Adams WT, Aitken SN (1998) Influence of second flushing on genetic assessment of cold hardiness in coastal Douglas-fir (Pseudotsuga menziesii var. menziesii (Mirb.) Franco). For Ecol Manag 111:119-126

Augspurger CK (1984) Seedling survival among tropical tree species: interactions of dispersal distance, light-gaps, and pathogens. Ecology 65:1705-1712

Barnola P, Alatou D, Lacointe A, Lavarenne S (1990) Étude biologique et biochimique du déterminisme de la croissance rythmique du chêne pédonculé (Quercus robur L). Effets de l'ablation des feuilles. Ann Sci For 21:619-631

Baucom RS, de Roode JC (2011) Ecological immunology and tolerance in plants and animals. Funct Ecol 25:18-28

Chuine I, Cour P (1999) Climatic determinants of budburst seasonality in four temperate-zone tree species. New Phytol 143:339-349

Collet C, Colin F, Bernier F (1997) Height growth, shoot elongation and branch development of young Quercus petraea grown under different levels of resource availability. Ann Sci For 54:65-81

Collin P, Badot PM, Millet B (1996) Croissance rythmique et développement du chêne rouge d'Amérique, Quercus rubra L, cultivé en conditions contrôlées. Ann Sci For 53:1059-1069

Dangl JL, Horvath DM, Staskawicz BJ (2013) Pivoting the plant immune system from dissection to deployment. Science 341:746-751

Desprez-Loustau ML, Dupuis F, Viguie A (1992) Evaluation of single applications of sterol-inhibiting fungicides for control of pine twisting rust. Plant Dis 76:376-382

Desprez-Loustau ML, Vitasse Y, Delzon S, Capdevielle X, Marçais B, Kremer A (2010) Are plant pathogen populations adapted for encounter with their host? A case study of phenological synchrony between oak and an obligate fungal parasite along an altitudinal gradient. J Evol Biol 23:87-97

Edwards MC, Ayres PG (1982) Seasonal changes in resistance of Quercus petraea (sessile oak) leaves to Microsphaera alphitoides. Trans Br Mycol Soc 78:569-571

Fornoni J (2011) Ecological and evolutionary implications of plant tolerance to herbivory. Funct Ecol 25:399-407

Gilbert GS (2002) Evolutionary ecology of plant diseases in natural ecosystems. Annu Rev Phytopathol 40:13-43

Gruntman M, Novoplansky A (2011) Ontogenetic contingency of tolerance mechanisms in response to apical damage. Ann Bot 108:965973

Guichoux E, Lagache L, Wagner S, Léger P, Petit RJ (2011) Two highly validated multiplexes (12-plex and 8-plex) for species delimitation and parentage analysis in oaks (Quercus spp.). Mol Ecol Resour 11: 578-585

Hajji M, Dreyer E, Marçais B (2009) Impact of Erysiphe alphitoides on transpiration and photosynthesis in Quercus robur leaves. Eur J Plant Pathol 125:63-72

Harmer R (1992) The incidence of recurrent flushing and its effect on branch production in Quercus petraea (Matt) Liebl growing in southern England. Ann Sci For 49:589-597

Hewitt HG, Ayres PG (1976) Effect of infection by Microsphaera alphitoides (powdery mildew) on carbohydrate levels and translocation in seedlings of Quercus robur. New Phytol 77:379-390

Jarvis PG (1964) The adaptability to light intensity of seedlings of Quercus petraea. J Ecol 52:545-571

Kovalchuk A, Keriö S, Oghenekaro AO, Jaber E, Raffaello T, Asiegbu FO (2013) Antimicrobial defenses and resistance in forest trees: challenges and perspectives in a genomic era. Annu Rev Phytopathol 51:221-244 
Lefevre T, Roche B, Poulin R, Hurd H, Renaud F, Thomas F (2008) Exploiting host compensatory responses: the 'must' of manipulation? Trends Parasitol 24:435-439

Lockhart BR, Hodges JD, Gardiner ES, Ezell AW (2003) Photosynthate distribution patterns in cherrybark oak seedling sprouts. Tree Physiol 23:1137-1146

Marçais B, Desprez-Loustau ML (2013) European oak powdery mildew: impact on trees, effects of environmental factors, and potential effects of climate change. Ann Sci For. doi:10.1007/s13595-0120252-x

Marçais B, Kavkova M, Desprez-Loustau ML (2009) Phenotypic variation in phenology of ascospore production between European populations of oak powdery mildew. Ann Sci For 66:814

McDowell N, Barnard H, Bond BJ, Hinckley T, Hubbard RM, Ishii H, Köstner B, Magnani F, Marshall JD, Meinzer FC et al (2002) The relationship between tree height and leaf area:sapwood area ratio. Oecologia 132:12-20

Mizumachi E, Mori A, Osawa N, Akiyama R, Tokuchi N (2006) Shoot development and extension of Quercus serrata saplings in responses to insect damages and nutrient conditions. Ann Bot 98:219-226

Montarry J, Corbière R, Andrivon D (2007) Is there a trade-off between aggressiveness and over-winter survival in Phytophthora infestans? Funct Ecol 21:603-610

Mougou A, Dutech C, Desprez-Loustau ML (2008) New insights into the identity and origin of the causal agent of oak powdery mildew in Europe. For Pathol 38:275-287

Mougou-Hamdane A, Giresse X, Dutech C, Desprez-Loustau ML (2010) Spatial distribution of genetically differentiated groups of oak powdery mildew fungi in France, using quick molecular detection methods. Ann Sci For 7:212

Packer A, Clay K (2000) Soil pathogens and spatial patterns of seedling mortality in a temperate tree. Nature 404:278-281
Pagan I, Alonso-Blanco C, Garcia-Arenal F (2008) Host responses in lifehistory traits and tolerance to virus infection in Arabidopsis thaliana. PLoS Pathog 4:e1000124

Pan JJ, Clay K (2003) Infection by the systemic fungus Epichloe glyceriae alters clonal growth of its grass host, Glyceria striata. Proc R Soc Lond B 270:1585-1591

Panstruga R, Dodds PN (2009) Terrific protein traffic: the mystery of effector protein delivery by filamentous plant pathogens. Science 324:748-750

Pap P, Rankovic B, Masirevic S (2012) Significance and need of powdery mildew control (Microsphaera alphitoides Griff. et Maubl. in the process of regeneration of the pedunculate oak (Quercus robur L.) stands in the Ravni Srem area. Period Biol 114:91-102

Percival GC, Noviss K (2008) Triazole induced drought tolerance in horse chestnut (Aesculus hippocastanum). Tree Physiol 28:16851692

Poulin R (2010) Parasite manipulation of host behavior: an update and frequently asked questions. In: Brockmann $\mathrm{HJ}$ (ed) Advances in the study of behavior, vol 41. Academic, Burlington, pp 151-186

Rosenberg DA, Robinson TL, Schupp JR, Engle-Ahlers CA, Meyer FW (2003) Effect of sterol-demethylation inhibiting fungicides on apple fruit set, fruit size, total yield, and gross returns. Hortscience 38 : 601-604

Roy BA, Kirchner JW (2000) Evolutionary dynamics of pathogen resistance and tolerance. Evolution 54:51-63

Sage RD, Koenig WD, McLaughlin BC (2011) Fitness consequences of seed size in the valley oak Quercus lobata Née (Fagaceae). Ann Sci For 68:477-484

SAS Institute Inc (2011) SAS ${ }^{\circledR} 9.3$ guide to software updates. SAS, Cary

Shykoff JA, Kaltz O (1998) Phenotypic changes in host plants diseased by Microbotryum violaceum: parasite manipulation, side effects and trade-offs. Int J Plant Sci 159:236-243 